Gut, 1985, 26, 1226-1232

\title{
Gastric lesions in portal hypertension: inflammatory gastritis or congestive gastropathy?
}

\author{
T T McCORMACK, J SIMS, I EYRE-BROOK, H KENNEDY, J GOEPEL, \\ A G JOHNSON, AND D R TRIGER

\begin{abstract}
From the University Departments of Surgery, Medicine and Pathology, Sheffield University, Royal Hallamshire Hospital, Sheffield
\end{abstract}

SUMMARY This paper reports the incidence and natural history of macroscopic gastritis in a series of 127 consecutive patients with portal hypertension of various aetiologies. Gastritis was observed endoscopically in 65 patients $(51 \%)$ and was of two main types. Twenty eight patients had severe or persistent gastritis which caused clinically significant bleeding on 80 occasions and accounted for $25 \%$ of the bleeds from all sources. The remainder had mild gastritis. The presence of gastritis seemed to be independent of the severity of liver disease or the degree of rise of wedged hepatic venous pressure and there was no difference in age, sex, or drugs prescribed in patients with or without gastritis. The mean follow up period and the mean number of sclerotherapy treatments was significantly greater $(p<0.005)$ in patients with gastritis. Full thickness gastric biopsies in seven surgical patients and 11 autopsy specimens showed dilated and tortuous submucosal veins. Endoscopic biopsies in 14 patients showed vascular ectasia in the mucosal layer which was in excess of the degree of inflammatory infiltrate. Gastritis occurred in patients with portal hypertension of all common aetiologies and the clinical and pathological evidence supports the contention that it reflects a congested gastric mucosa and should be renamed congestive gastropathy. As injection sclerotherapy improves survival from variceal bleeding congestive gastropathy may become more common. The response to conventional ('anti-erosive') therapy is poor and measures aimed at reducing the gastric portal pressure may be the only effective means of treating this condition.

Gastric mucosal lesions are common in portal hypertension. They are an important cause of blood loss, which may be slow and insidious causing anaemia ${ }^{1}$ or sudden and severe, causing massive and occasionally fatal haemorrhage. ${ }^{2}$ The use of sclerotherapy for bleeding oesophageal varices combined with regular endoscopic follow up has provided a unique opportunity to study the progression of changes occurring in the gastric mucosa. We report our clinical and endoscopic experience of gastritis in portal hypertension over a four year period.

\section{Methods \\ PATIENTS \\ Definition of gastritis \\ The endoscopic changes which occur in the gastric \\ Address for correspondence: Dr D R Triger, Department of Medicine, Royal Hallamshire Hospital. Sheffield, S10 2JF. \\ Received for publication 24 January 1985}

mucosa were classified according to the description of Taor et al. ${ }^{3}$ (i) a fine pink speckling or 'scarlatina' type rash, (ii) a superficial reddening, particularly on the surface of the rugae giving a striped appearance, (iii) a fine white reticular pattern separating areas of raised red oedematous mucosa resembling a 'snake skin'.

These were included under the term 'mild gastritis'.

During the course of the study two additional forms of gastric mucosal changes were noted: (i) discrete red spots analogous to the cherry red spots described in the oesophagus. ${ }^{4}$ These spots can become confluent giving a local area of severe gastritis which may bleed, (ii) a diffuse haemorrhagic gastritis.

These were termed 'severe gastritis'.

Gastritis has been arbitrarily defined as 'transient' if present at one endoscopy and resolved by the next endoscopy six to eight weeks later. If gastritis was 
present for more than eight weeks at two or more consecutive endoscopies it was said to be 'persistent'. Gastritis occurring within two weeks of balloon tamponade was excluded as this could be because of contact irritation.

Over the last four years (August 1979-August 1983) 127 patients with portal hypertension have attended this unit. One hundred and fourteen patients presented with bleeding and a further 13 had oesophageal varices with no clinical evidence of haemorrhage. These were discovered during routine evaluation of their portal hypertension. The presence or absence, and the degree of gastritis was noted at each endoscopy. All patients were endoscoped at presentation by an experienced endoscopist and any patient with upper gastrointestinal tract bleeding underwent emergency endoscopy. Any patients with oesophageal varices were treated by injection sclerotherapy and followed up by regular check endoscopies.

\section{PATHOLOGY TECHNIQUE}

Biopsies of the stomach were studied in 41 patients with portal hypertension. These samples were obtained (a) at endoscopy (23 patients - nine with macroscopically normal mucosa and 14 with gastritis), (b) during surgical procedures (seven patients four with bleeding gastritis and three with bleeding gastric varices) and (c) at necropsy (11 patients). Further operative samples were also taken during refashioning of an ileostomy and at resection of an oesophagojejunal anastomosis. Two patients with duodenitis also had endoscopic biopsies taken. Endoscopic biopsies and surgical specimens were fixed by immersion in formal saline. Post mortem specimens were fixed by gently filling the unopened stomach and oesophagus with formal saline and immersing the whole specimen in formal saline. Paraffin sections were prepared and stained by haematoxylin and eosin ( $\mathrm{H}$ and $\mathrm{E}$ ) or Miller's elastic stain counterstained by van Gieson's stain for collagen (EVG).

\section{Results}

\section{ENDOSCOPIC FINDINGS}

Sixty five patients $(51 \%)$ had macroscopic gastritis at some stage during follow up. The changes were most commonly seen in the fundus and body of the stomach. There was no significant difference in age or sex in patients with gastritis compared with the rest (Table 1). Although there was a trend for gastritis to be more frequent in patients with less severe liver disease (as assessed by Child's grading) ${ }^{5}$ this did not reach statistical significance $(0.05<p<0 \cdot 10)$. Gastritis occurred in portal
Table 1 Clinical features of 65 patients with gastritis compared with 62 patients with no gastritis

\begin{tabular}{lll}
\hline & \multicolumn{2}{l}{ Patients (no) } \\
\cline { 2 - 3 } $\begin{array}{lll}\text { Cause of portal } \\
\text { hypertension }\end{array}$ & $\begin{array}{l}\text { Without } \\
\text { gastritis (62) }\end{array}$ & $\begin{array}{l}\text { With } \\
\text { gastritis(65) }\end{array}$ \\
\hline Alcoholic cirrhosis & 14 & 23 \\
Primary biliary cirrhosis & 13 & 13 \\
Chronic active hepatitis & 9 & 12 \\
Cryptogenic cirrhosis & 10 & 4 \\
Portal vein thrombosis & 7 & 5 \\
Others & 9 & 8 \\
Child's grading A & 21 & 31 \\
& 15 & 17 \\
B & 26 & 17 \\
Age (Mean \pm SD) & $57 \cdot 5( \pm 12 \cdot 1)$ & $54 \cdot 5( \pm 14 \cdot 1)$ \\
Sex Male & 34 & 35 \\
\multicolumn{1}{c}{ Female } & 28 & 30 \\
\hline
\end{tabular}

hypertension of all common aetiologies and the proportion of patients who developed gastritis in each of the aetiological groups was not significantly different $\left(\chi^{2}\right.$ test $)$.

Patients with gastritis had a significantly greater $(p<0.005)$ number of sclerotherapy treatments per patient (mean $4 \cdot 0 \pm 0.3 \mathrm{SE}$ ) than those without gastritis (mean $2 \cdot 3 \pm 0 \cdot 2 \mathrm{SE}$ ). The follow up period in patients with gastritis (mean 13.8 months $\pm 1.5 \mathrm{SE}$ ) was also significantly greater $(p<0.005)$ than in the non-gastritis group (mean 6.7 months $\pm 1.2 \mathrm{SE}$ ).

Mild gastritis was noted in 37 of the 65 patients. This was not of any clinical significance and in only two patients did this progress to severe gastritis. On the other hand severe gastritis led to clinical bleeding in almost all instances (see below). Gastritis both mild and severe was noted on initial presentation in about one third of patients, and developed during follow up in the remainder. The age, sex, and Child's grading(s) was similar in patients with mild transient gastritis and in those with severe or persistent gastritis (Table 2), but both the mean follow up period and the number of sclerotherapy treatments were significantly greater $(\mathrm{p}<0.0025$ and $\mathrm{p}<0.005$ respectively) in the patients with severe or persistent gastritis. The mean number of treatments per patient month, however, was similar in both groups.

\section{BLEEDING}

Clinically significant bleeding from gastritis occurred on 80 occasions in 29 patients, and blood transfusion (2-15 units) was required for 60 bleeds. Bleeds from gastritis accounted for $25 \%$ of the total number of bleeds from all sources (Table 3). Gastritis was responsible for only nine of 114 
Table 2 Clinical features of 65 patients with gastritis

\begin{tabular}{|c|c|c|c|}
\hline & $\begin{array}{l}\text { Persistent or } \\
\text { severe gastritis } \\
(28)\end{array}$ & & $\begin{array}{l}\text { Mild } \\
\text { gastritis } \\
\text { (37) }\end{array}$ \\
\hline $\begin{array}{l}\text { Age mean } \pm S E \\
\text { range } \\
\text { Sex male } \\
\text { female }\end{array}$ & $\begin{array}{l}52 \cdot 0 \pm 2 \cdot 5 \\
(31-79) \\
15 \\
13\end{array}$ & $(\mathrm{NS})^{*}$ & $\begin{array}{l}56 \cdot 9 \pm 2 \cdot 8 \\
(21-84) \\
20 \\
17\end{array}$ \\
\hline $\begin{array}{l}\text { Follow-up (mont } \\
\text { mean } \pm S E \\
\text { range }\end{array}$ & $\begin{array}{l}\text { s) } \\
17 \cdot 8 \pm 2 \cdot 3 \\
1 \text { day-4 years }\end{array}$ & $(p<0.0025)^{*}$ & $\begin{array}{l}8.9 \pm 1 \cdot 5 \\
1 \text { day }-2 \cdot 2 \text { years }\end{array}$ \\
\hline $\begin{array}{c}\text { Child's grade } \\
\text { A } \\
\text { B } \\
\text { C }\end{array}$ & $\begin{array}{r}14 \\
8 \\
6\end{array}$ & $(\mathrm{NS}) \dagger$ & $\begin{array}{r}17 \\
9 \\
11\end{array}$ \\
\hline $\begin{array}{l}\text { Sclerotherapy } \\
\text { treatment per pa } \\
\text { mean } \pm S E \\
\text { treatment per pa } \\
\text { month mean }\end{array}$ & $\begin{array}{l}\text { ent } \\
5 \cdot 3 \pm 0 \cdot 5 \\
\text { ent } \\
0.39 \pm 0.07\end{array}$ & $\begin{array}{l}(p<0 \cdot 005)^{*} \\
(N S)^{*}\end{array}$ & $\begin{array}{l}2 \cdot 8 \pm 0 \cdot 3 \\
0 \cdot 51 \pm 0 \cdot 09\end{array}$ \\
\hline
\end{tabular}

* Students $t$ test for unpaired numbers. $+\chi^{2}$ test.

presenting bleeds, but after initial sclerotherapy, it accounted for over one third of rebleeding episodes. Fifty one bleeds from gastritis occurred in the presence of thrombosed or obliterated oesophageal varices. In the presence of patent oesophageal varices, bleeding from gastritis was diagnosed only if it was seen to be coming from an area of gastritis and no other source of haemorrhage was identifiable.

WEDGED HEPATIC VENOUS PRESSURE

Wedged hepatic venous pressure (WHVP) was measured in 18 patients with oesophageal varices

Table 3 Sites of presenting bleeds in 114 patients and 202 subsequent bleeds in 48 patients who rebled

\begin{tabular}{lcc}
\hline Site of bleeding & Presenting bleed & Subsequent bleed \\
\hline Oesophageal varices & 88 & 64 \\
Gastritis & 9 & 71 \\
Upper GI tract & - & 13 \\
$\quad$ unknown site) & - & 16 \\
Post injection slough & 6 & 11 \\
Gastric varices & 4 & 3 \\
Peptic ulcer & - & 3 \\
Duodenitis & - & 14 \\
Oesophagogastric junction & 1 & 1 \\
Mallory Weiss & 3 & 2 \\
Rectal varices & 1 & 4 \\
Oesophagojejunal & 1 & - \\
$\quad$ anastomosis & 1 & - \\
Intra-abdominal & 114 & 202 \\
Ileostomy & & \\
\end{tabular}

who had not bled before the study. There was no significant difference in the mean pressure in the 12 with gastritis (mean WHVP $17.3 \mathrm{mmHg} \pm 1.6 \mathrm{SE}$ ) compared with those who had no gastritis (mean WHVP $16 \cdot 0 \mathrm{mmHg} \pm 1 \cdot 6 \mathrm{SE}$ ).

\section{RELATION OF MEDICATION TO GASTRITIS}

Seventy patients were receiving diuretics, 11 patients penicillamine, six patients corticosteroids and 13 patients were being treated for diabetes. Patients receiving these drugs were equally distributed between the gastritis and non-gastritis groups.

\section{EFFECT OF SCLEROTHERAPY ON GASTRITIS}

In six patients gastritis appeared for the first time after successful sclerotherapy while in another five patients the obliteration of oesophageal varices appeared to coincide with the disapppearance of gastritis.

\section{PATHOLOGICAL CHANGES}

The most consistent finding was dilatation of the submucosal veins which were tortuous and irregular in diameter. Elastic staining emphasised the irregularity of the vein wall and showed foci of intimal thickening (Fig. 1). These features were visible in veins sampled from all areas of the stomach but were particularly prominent in the proximal part of the gastric body and cardia. The mucosal vessels showed focal areas of abnormality. These consisted of ectasia of capillaries and veins (Fig. 2) which at times formed a leash of mucosal vessels. In some cases this could be seen to overlie areas of abnormal submucosal veins. Although chronic gastritis as characterised by mononuclear infiltrate did occasionally occur, the vascular changes were usually in excess of that expected with the degree and activity of gastritis. We have termed these changes 'congestive gastropathy'.

In the jejunal and ileal surgical samples and duodenal biopsies there was also marked vascular ectasia in the mucosa, (Fig. 3) with no evidence of an inflammatory infiltrate.

\section{ENDOSCOPIC SPECIMENS}

Biopsies were not done in endoscopically severe gastritis for fear of inducing major haemorrhage. Classic histological features of chronic inflammatory gastritis were seen in four of 14 patients, while the other 10 had vascular ectasia with little or no inflammatory infiltrate. Six of the nine biopsies from macroscopically normal mucosa were histologically normal, the remainder showing vascular ectasia. It should be remembered, however, that endoscopic biopsies are of necessity small and superficial and therefore liable to sampling error. 


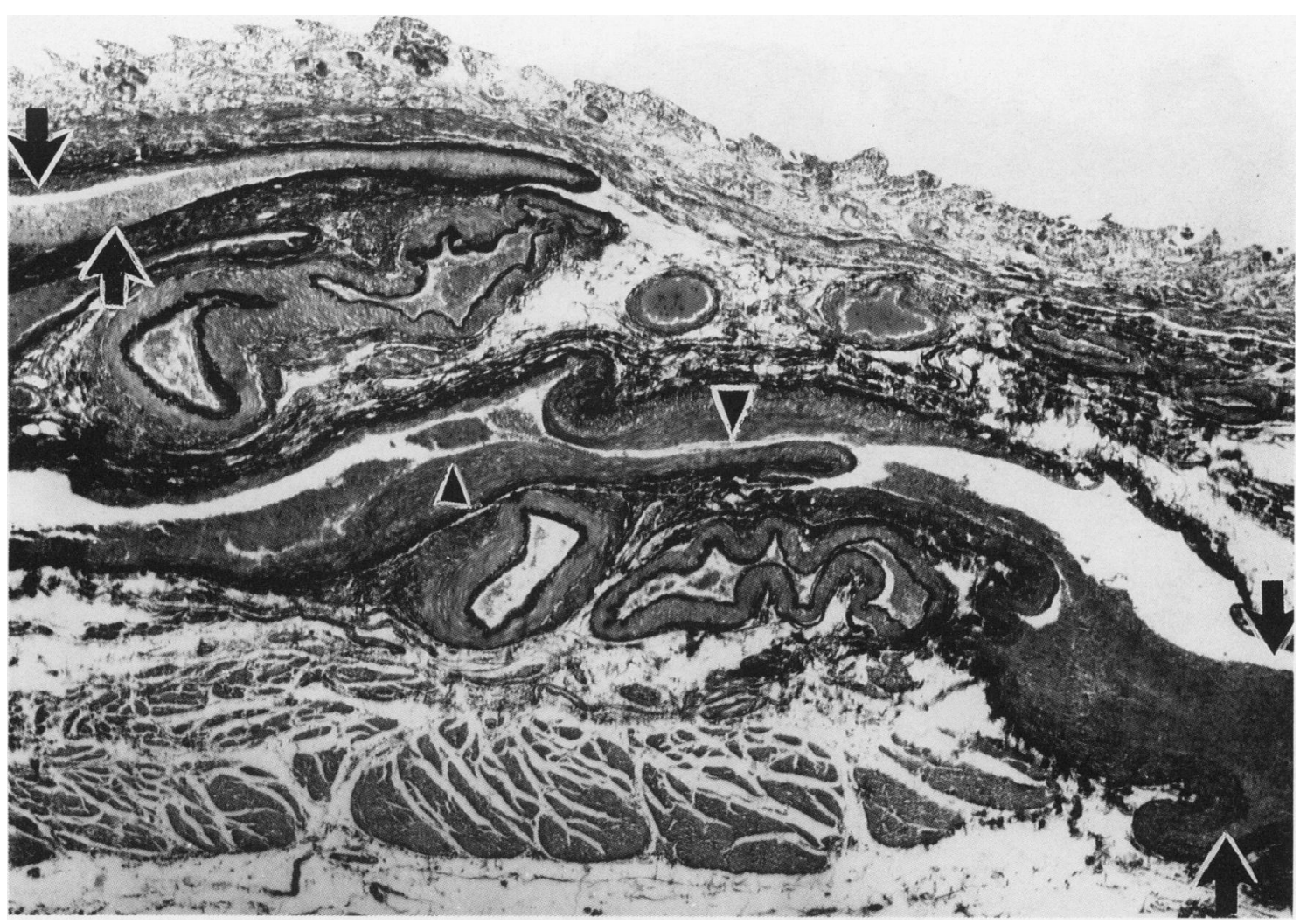

Fig. 1 Dilated submucosal veins (arrows to walls) with intimal thickening (arrow heads). (Post mortem stomach, elastic van Gieson, $\times 8$ original magnification).

\section{SURGICAL SPECIMENS}

These were taken from patients with severe gastritis or bleeding gastric varices and all showed mucosal and submucosal vascular abnormalities.

\section{AUTOPSY SPECIMENS}

Marked submucosal vascular ectasia was seen in all cases, but mucosal vascularity could not be assessed because of mucosal post mortem autolysis.

The correlation between the macroscopic appearances and histological findings are summarised in Table 4.

\section{Discussion}

In this series, gastritis has been observed at some time in $51 \%$ of patients with oesophageal varices and it has been responsible for $25 \%$ of the total number of bleeds. Other workers have noted that bleeding in portal hypertension can be caused by gastritis in $30-40 \%$ of cases. ${ }^{678}$ Gastric mucosal changes were seen in portal hypertension of all aetiologies and occurred in patients with both patent and obliterated varices.

It should be emphasised that, with the exception of the cherry red spots, the gastritis described here is macroscopically identical to that seen in patients without portal hypertension, but the histological appearance is quite different from that described by

Table 4 Summary of macroscopic and histological findings in gastric specimens

\begin{tabular}{ccll}
\hline $\begin{array}{l}\text { Type of } \\
\text { specimen }\end{array}$ & No & $\begin{array}{l}\text { Macroscopic } \\
\text { appearance }\end{array}$ & $\begin{array}{l}\text { Microscopic } \\
\text { appearance }\end{array}$ \\
\hline $\begin{array}{c}\text { Endoscopic } \\
\text { biopsy }\end{array}$ & 9 & Normal & $\begin{array}{l}6 \text { normal } \\
\text { mucosal ectasia }\end{array}$ \\
$\begin{array}{c}\text { Endoscopic } \\
\text { biopsy }\end{array}$ & 14 & Mild gastritis & $\begin{array}{l}4 \text { inflammatory } \\
10 \text { mucosal ectasia }\end{array}$ \\
Surgical & 7 & $\begin{cases}4 \text { severe gastritis } \\
3 \text { bleeding gastric } \\
\text { varices }\end{cases}$ & $\begin{array}{l}\text { All mucosal and } \\
\text { submucosal } \\
\text { ectasia }\end{array}$ \\
Autopsy & 11 & - & $\begin{array}{l}\text { All submucosal } \\
\text { ectasia }\end{array}$ \\
\hline
\end{tabular}




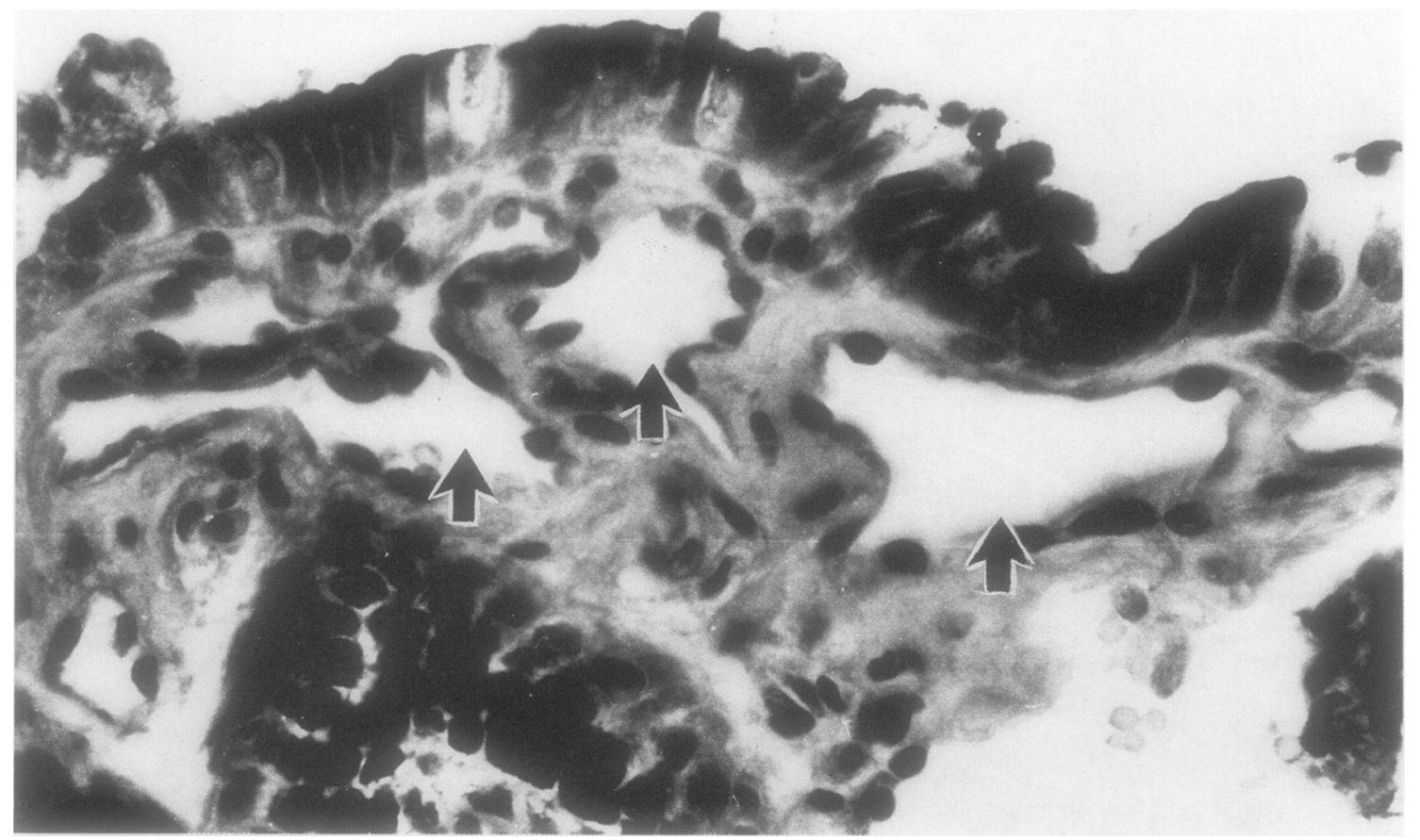

Fig. 2 Gastric antral biopsy showing prominent dilated vessels (arrows) near the surface. (PAS $\times 160$ original magnification).

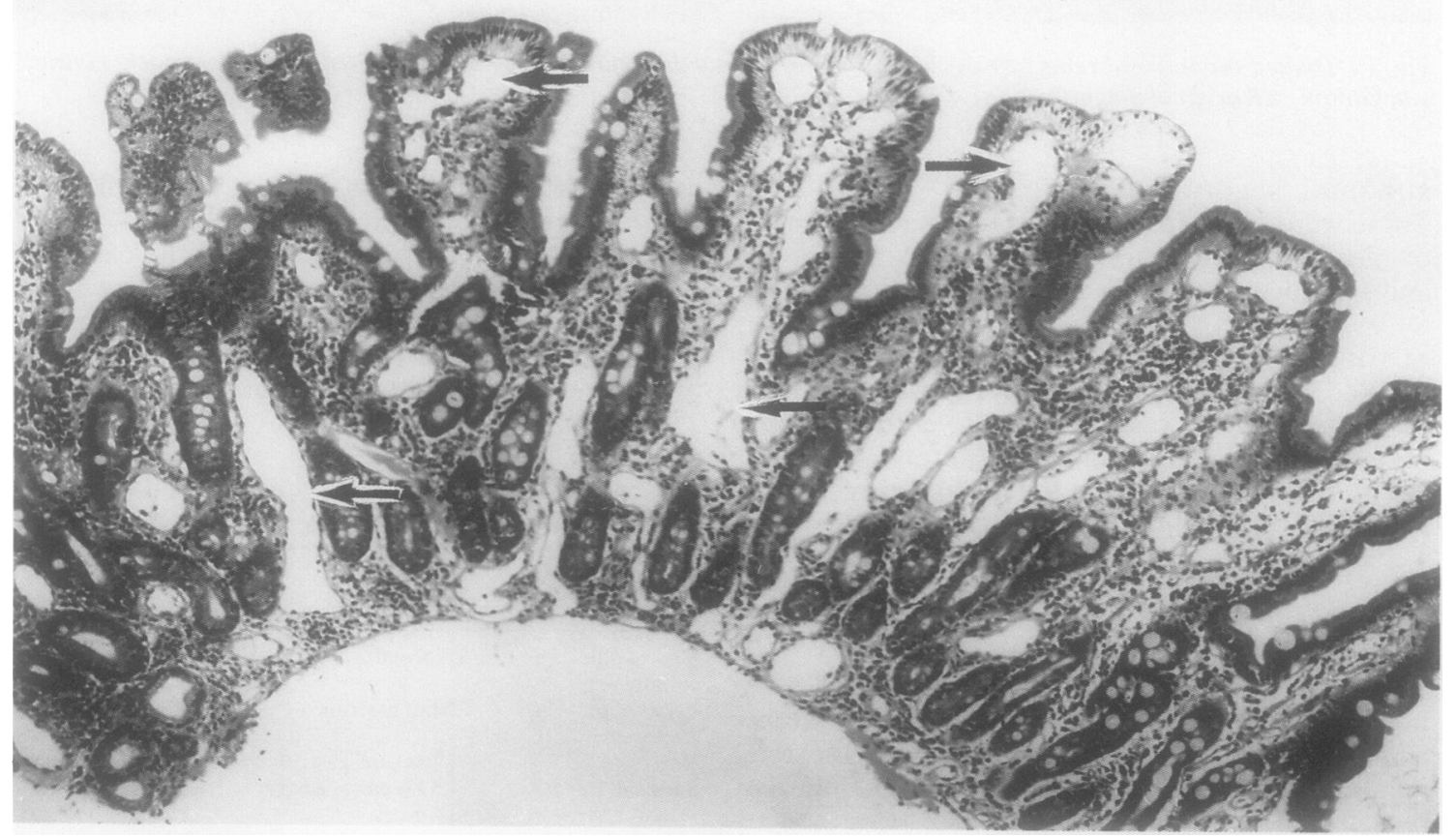

Fig. 3 Duodenal biopsy showing marked vascular ectasia (arrows) particularly in the villi. Acute inflammatory changes are absent. ( $H \& E \times 20$ original magnification $)$. 
Whitehead and colleagues ${ }^{9}$ where chronic inflammatory cells predominate and there is a strong association with gastric ulcer. Our observations are similar to that of Brown and colleagues ${ }^{10}$ who found no evidence of an increased incidence of classical chronic gastritis in a series of cirrhotics, despite the presence of gastric ulcers and erosions in nearly $20 \%$ of their patients. Furthermore, they comment that gastric erosions tended to occur in histologically normal mucosa. Their study, however, did not include assessment of the mucosal and submucosal vascular channels.

Gastritis in portal hypertension might be caused by several factors. Alcohol can be excluded because we have observed the changes in non-alcoholic cirrhosis as frequently as in alcoholic cirrhosis. The observation of severe gastritis in two patients who had undergone truncal vagotomies makes it unlikely that gastric acid plays a major role.

The most important element causing gastritis may be the raised portal pressure itself. Obstruction of the venous drainage from the stomach can induce changes in the gastric mucosa. Palmer, in $1957^{11}$ induced portal hypertension in dogs by portal vein ligation and found that both the mucosal and submucosal veins in the stomach wall became dilated. Both he and Sandblom ${ }^{12}$ observed similar changes in gastric biopsies from patients with portal hypertension. Alternatively gastritis might be because of gastric mucosal ischaemia secondary to arteriovenous shunting which can be demonstrated in the stomachs of both animals ${ }^{13}$ and humans ${ }^{14}$ with portal hypertension.

The histological changes are entirely consistent with an increase in venous pressure producing a congested gastric mucosa. The occurrence and severity of this congestive gastropathy may depend, however, not only on the total level of portal pressure but also on local blood flow characteristics which may or may not transmit this increased pressure to the gastric mucosal and submucosal veins. Differences in local blood flow patterns may explain why some patients develop gastropathy and others do not. Successful sclerotherapy of oesophageal varices may induce local changes in blood flow patterns and if this results in an increased venous pressure in areas proximal to the site of thrombosis, congestive gastropathy might be predicted.

The mean number of sclerotherapy treatments in patients with gastropathy was significantly greater than in those without it. Sclerotherapy appears to increase long term survival ${ }^{15}$ and the greater incidence of the gastric lesion in the longer survivors may be related either to the progression of disease or to the greater number of sclerotherapy treat- ments in these patients. Our experience suggests that while gastropathy may develop after sclerotherapy in some individuals the converse is true in others. In theory obstruction of blood flow at the gastro-oesophageal junction may increase congestion by blood vessels flowing from the stomach. This effect is likely to be very variable as recent studies using Doppler ultrasound ${ }^{16}$ have shown that blood flow in oesophageal varices may sometimes be towards the stomach and therefore thrombosis of these varices would reduce and certainly not induce congestion in the gastric mucosa. In the majority of patients, therefore, the relationship between sclerotherapy and gastropathy is not straightforward and the presence of the gastric lesion is probably independent of the patency of oesophageal varices.

\section{THERAPEUTIC IMPLICATIONS}

Congestive gastropathy was mild and transient in more than half of the patients. Complications did not occur and progression was uncommon during the short period of follow up. In contrast, patients with severe or persistent gastropathy are prone to clinically significant haemorrhage.

Twenty five of our patients with severe changes received $\mathrm{H}_{2}$ receptor antagonists, five received sucralfate and all were prescribed antacids at some stage. None of these agents had any significant effect upon either the gastritis or the bleeding. This tends to support the hypothesis that it is congestion rather than erosion which is the major factor damaging the gastric mucosa. The rational approach to treatment is therefore a reduction of the portal venous pressure which should thus reduce the congestion in the gastic mucosa. ${ }^{2}$.

Portosystemic shunting effectively reduces portal pressure and bleeding from gastritis is rare after this procedure. ${ }^{217-19}$ An alternative surgical approach is to reduce the gastric blood flow alone by devascularising the upper two thirds of the stomach and combining it with an oesophageal transection. We have used this procedure in eight patients, specifically for controlling severe haemorrhagic gastritis and it has been successful in five. As with portosystemic decompression this procedure is not without considerable risk in patients with advanced liver disease.

Methods aimed at reducing portal blood pressure or flow by pharmacological means would clearly be preferable to surgery. Although Lebrec and colleagues ${ }^{20}$ reported that propranolol reduced variceal haemorrhage, close inspection of their paper reveals that the drug also reduced the incidence of gastritis. On an anecdotal basis we have observed significant improvement in several patients with severe persis- 
tent gastritis treated with propranolol and we are currently evaluating its effectiveness by means of a controlled trial.

In conclusion, the macroscopic gastritis noted in patients with portal hypertension differs from that seen in the absence of liver disease in that (a) the histological appearance is quite distinct (b) it is unrelated to the aetiology of the portal hypertension (c) it does not respond to conventional antiinflammatory drug therapy and (d) the histological changes are found elsewhere in the gastrointestinal tract. In the light of the clinical, haemodynamic and histological observations the term 'congestive gastropathy' appears to be more appropriate.

We wish to thank those involved with the care of these patients. Sister Salisbury and the staff of the endoscopy unit, Sisters Ellis and Barry, and the staff in the operating theatres.

\section{References}

1 Wenger J, Huffman RT, Landy MS. Persistent blood loss from the stomach of patients with cirrhosis and oesophageal varices. South Med J 1970; 63: 560-6.

2 Sarfeh IJ, Juler GL, Stemmer EA, Mason GR. Results of surgical management of haemorrhagic gastritis in patients with gastroesophageal varices. Surg Gynecol Obstet 1982; 155: 167-70.

3 Taor RE, Fox B, Ware J, Johnson AG. Gastritis gastroscopic and microscopic. Endoscopy 1975; 7: 209-15.

4 Japanese Research Society for Portal Hypertension. The general rules for recording endoscopic findings on oesophageal varices. Jap J Surg 1980; 10: 84-7.

5 Pugh RNH, Murray-Lyon IM, Dawson JL, Pietroni $\mathrm{MC}$, Williams R. Transection of the oesophagus for bleeding oesophageal varices. $B r J$ Surg 1973; 60: 646-9.

6 Dagradi AE, Mehler R, Tan DT, Stempien SJ. Sources of upper gastrointestinal bleeding in patients with liver cirrhosis and large esophagogastric varices. $\mathrm{Am} \mathrm{J}$ Gastroenterol 1970; 54: 458-63.
7 Thomas E, Rosenthal WS, Rymer W, Katz D. Upper gastrointestinal haemorrhage in patients with alcoholic liver disease and oesophageal varices. Am J Gastroenterol 1979; 72: 623-9.

8 Khodadoost J, Glass GBJ. Erosive gastritis and acute gastroduodenal ulcerations as source of upper gastrointestinal bleeding in liver cirrhosis. Digestion 1972; 7: 129-38.

9 Whitehead R, Truelove SC, Gear MWL. The histological diagnosis of chronic gastritis in fibreoptic gastroscope biopsy specimens. J Clin Pathol 1972; 25: $1-11$.

10 Brown RC, Hardy GJ, Temperley JM, Miloszewski KJA, Gowland G, Losowsky MS. Gastritis and cirrhosis - no association. J Clin Pathol 1981; 34: 744-8.

11 Palmer ED. Erosive gastritis in cirrhosis. Am J Dig Dis 1957; 2: 31-6.

12 Sandblom $P$. The source of bleeding in portal hypertension. Bull Soc Int Chin 1975; 3: 165-7.

13 Manabe T, Suzuki T, Honjo I. Changes of gastric blood flow in experimentally induced cirrhosis of the liver. Surg Gynecol Obstet 1978; 147: 753-7.

14 Hashizume M, Tanaka K, Inokuchi K. Morphology of gastric microcirculation in cirrhosis. Hepatology 1983; 6: $1008-12$.

15 MacDougall BRD, Westaby D, Theodossi A, Dawson $\mathrm{JL}$, Williams $\mathrm{R}$. Increased long-term survival in variceal haemorrhage using injection sclerotherapy. Results of a controlled trial. Lancet 1982; 1: 124-7.

16 McCormack T, Smallwood RH, Walton L, Martin T, Robinson P, Johnson AG. Doppler ultrasound probe for assessment of blood-flow in oesophageal varices. Lancet 1983; 2: 677-8.

17 Jackson FC, Perrin EB, Felix WR, Smith AG. A clinical investigation of the portacaval shunt: V. survival analysis of the therapeutic operation. Ann Surg 1971; 174: 672-701.

18 Resnick RH, Iber FL, Ishihara AM, Chalmers TC, Zimmerman H. A controlled study of the therapeutic portacaval shunt. Gastroenterology 1974; 67: 843-57.

19 Rueff B, Prandi D, Degos F et al. A controlled study of therapeutic portacaval shunt in cirrhosis. Lancet 1976; 1: 655-9.

20 Lebrec D, Poynard T, Hillon P, Benhamou JP. Propranolol for prevention of recurrent gastrointestinal bleeding in patients with cirrhosis. $N$ Engl J Med 1981; 305: $1371-4$. 